\title{
Doğuştan çarpık ayakta patolojik anatomi ve kinematik
}

\section{Congenital clubfoot pathologic anatomy and kinematics}

\author{
Adnan Sevencan, Erol Göktürk \\ Eskişehir Osmangazi Üniversitesi Tıp Fakültesi, Ortopedi ve Travmatoloji Anabilim Dalı, Eskişehir
}

Doğuştan çarpık ayak, etiyolojisi kesin bilinmemekle beraber, sık görülen doğumsal bir hastalıktır. Ayak orta ve ön kısmında adduksiyon, arka kısmında varus, bilek ekleminde ekinus ve kavus deformiteleri ile karakterizedir. Talus kemiği, talo-kalkaneo-naviküler eklemler ve mediyal yumuşak doku kontraktürleri, patolojideki ana etmenlerdir. Bu makale çarpık ayaktaki güncel patolojik anatomi bulgularını ve bunlara bağlı gelişen kinematik bozuklukları gözden geçirecektir.

Anahtar sözcükler: çarpık ayak; talipes ekinovarus; patoloji; anatomi; alçı kalıpları
Clubfoot (congenital talipes equinovarus) is a common congenital abnormality with uncertain etiology. It is characterized by the presence of forefoot and midfoot adductus, hindfoot varus, ankle equinus, and cavus. Talus bone, talo-calcaneo-navicular joints and medial soft tissues contractures are the mainstone of the pathology. This article is a review of the findings on patho-anatomy of congenital talipes equinovarus and related kinematic disorders.

Key words: clubfoot; talipes equinovarus; pathology; anatomy; plaster casts
Y etmiş yıl yaşayan bir insan, 25.550 günlük ömründen uyku zamanı olarak günde sekiz saat çıkartıldığında, kalan yaklaşık 17.000 günlük ömrünü bir şekilde ayakta geçiriyor demektir. Bu sürenin rahat yürüyerek geçirilmesi, normal bir anatomi ve fizyolojiye sahip bir çift ayakla mümkün olmaktadır. Bu nedenle, daha doğumunda normal anatomik yapıya sahip olmayan ve geleceği tamamı ile aile ilgisi ve uygun bir doktor tedavisine bağlı olan, doğuştan çarpık ayaklı (DÇA'lı) çocuklara ileri bir tedavi sunabilmek, bir yerde, bu hastalığın etiyolojisini ve patolojik anatomisini bilmekten geçmektedir. ${ }^{[1]}$ Çarpık ayağın 1000 canlı doğumdan birinde ve $\% 50$ bilateral görüldüğü bilinirse, ${ }^{[1,2]} 80$ milyona yakın nüfusumuzda oluşturduğu olumsuz psiko-sosyal ve ekonomik etkilerin ciddiyeti çok daha iyi kavranabilir.

Son yıllarda, gerek düşük olmuş fetüsler ve yenidoğanların ayaklarından alınan makroskopik ve mikroskopik doku örnekleri, üç-boyutlu bilgisayarlı tomografi (3D-BT) ve manyetik rezonans (MR) incelemeleri, gerekse cerrahilerden elde edilen bilgilerle; bu bozukluğun mevcut makroskopik ve mikroskopik patolojileri çok daha ayrıntılı olarak ortaya konmaktadır. ${ }^{[3-13]}$ Tüm bu gelişmelerin sonucunda, geçmişe oranla DÇA tedavisinde çok daha başarılı sonuçlar alınabilmektedir.

DÇA'da etiyoloji kesin olarak bilinmese de, çeşitli genetik ve çevresel etmenlerin rolü olduğu ileri sürülmektedir. ${ }^{[4]}$ Güncel yaygın olan tedavileri ise; düzeltici seri manipülasyon ve alçlamalar, breyslemeler, seyrek olarak da aşil tenotomileri ve diğer cerrahi girişimleri içerir. ${ }^{[14]}$

\section{KEMIKSEL PATOLOJILER}

DÇA'yı daha iyi anlamak için, normal ayak bileği, ayak anatomisi ve ayak biyomekaniği konusunda bilgi sahibi olmak gerekir. Tibiotalar eklem, temel olarak mediyal ve lateral malleoller arasında sınırlanan mortis içerisindeki talus kubbesinin sagittal planda rotasyon yaptığı menteşe tipi bir eklemdir. Talusa herhangi bir kas yapışmadığı için, hareketleri kalkaneus ve navikulaya yapışan bağlar tarafından belirlenir. Talus, kalkaneus ve naviküler kemik arasındaki ilişki, talo-kalkaneonaviküler eklem ya da eklem kompleksi olarak adlandırılır. Bu eklem, dört eklem yüzeyini içerir ve bir "topuz ve yuva" (ball-and-socket eklem) ekleme benzer. Topuz,

- Illetişim adresi: Yard. Doç. Dr. Adnan Sevencan, ESOGU Tıp Fakültesi, Ortopedi ve Travmatoloji Anabilim Dalı, El Cerrahisi Bilim Dalı, Eskişehir Tel: 0530 - 0610361 e-posta: adnansevencan@hotmail.com

- Geliş tarihi: 25 Mayıs 2015 Kabul tarihi: 25 Mayıs 2015 

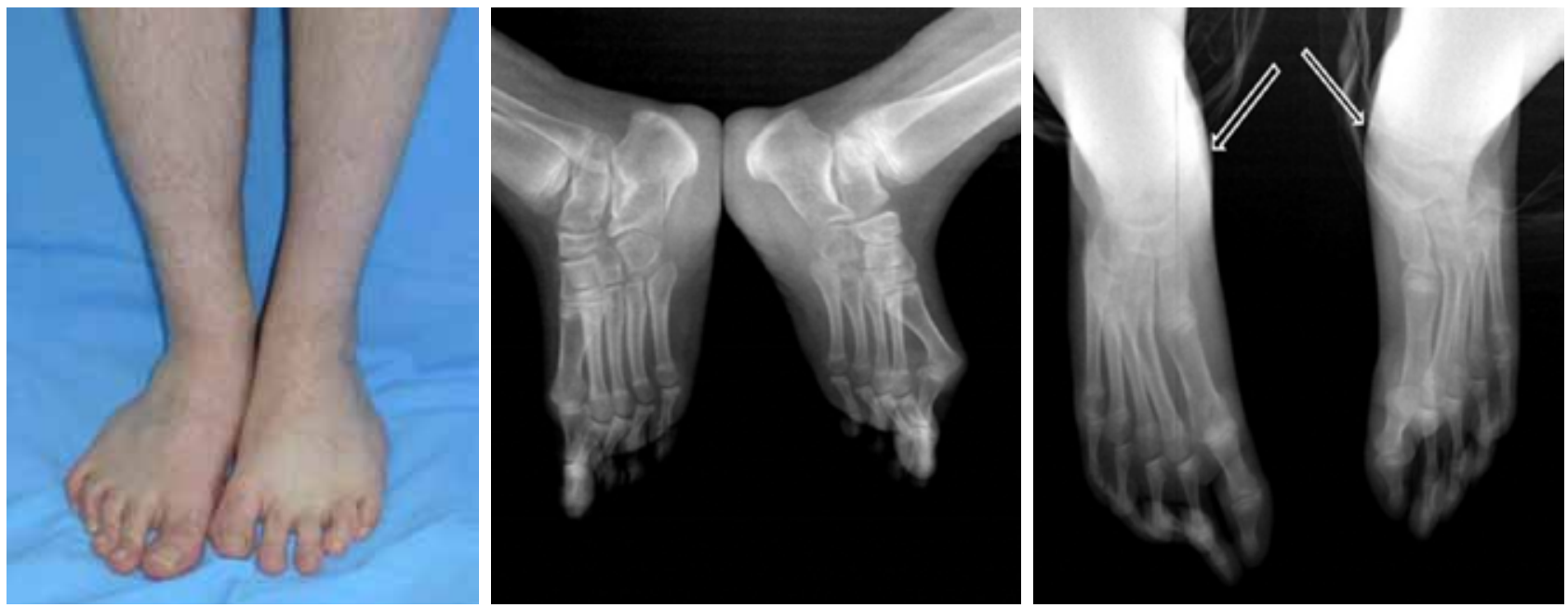

Şekil 1. a-c. Çocukluğunda sol çarpık ayak için alçı düzeltmeleri ve cerrahi tedavi görmüş 25 yaşında bir olgunun güncel görünümü (a). Tibia boyları solda $3 \mathrm{~cm}$ kısa, baldır ortası çapı solda $5 \mathrm{~cm}$ hipotrofik, ayak uzun aksı solda $3,5 \mathrm{~cm}$ kısa ve sol ayak enliliği ise sağ normal ayaktan $1 \mathrm{~cm}$ geniş. Radyolojik görüntü ve talonavikular kemiklerin mediyalize pozisyonu (b ve c, oklar).

talus başıdır. Talus başı, navikulanın konkav yüzü ve kalkaneusun ön ve orta fasetinden oluşan yuvaya oturur. Yuvanın geri kalan kısmını; talonaviküler eklem kapsülü, tibialis posterior tendonu, deltoid, kalkaneonaviküler (spring), "Y" veya çatal biçiminde (bifurcated) ve interosseöz talokalkaneal bağlardan oluşan, konnektif bağ dokusu oluşturur. ${ }^{[15]}$

DÇA'nın fiziksel görünümü ise; kavus, adduksiyon, varus ve ekinus olarak dört ana komponentten oluşan, üç boyutlu bir şekil bozukluğudur. ${ }^{[1,15,16]} \mathrm{Bu}$ komponentlere sıklıkla tibial internal torsiyon da eşlik etmektedir. ${ }^{1}$ Ancak, bu torsiyonun tartışılır olduğunu belirten yayınlar da vardır. ${ }^{[17,18]}$ Ayak bileği, subtalar eklemler ve orta ayak kemiklerinin tümü ve metatarsal kemikler, hastalığa değişen şiddetlerde katılmaktadır. ${ }^{1}$

DÇA'da ana kemik deformitesi, talustadır. Talus boynu, mediyale ve plantara deviyedir. ${ }^{15}$ Tüm talus, ekinusta durur. Dinamik manyetik rezonans (MR) ve ultrasonik görüntülemelerin de katkısı ile, talusun kıkırdak taslağının karşı taraftaki normal talustan \%20 daha küçük olduğu saptanmıştır. Ayrıca, talar ossifikasyon merkezi \%40 daha küçüktür ve bu, gelişimsel gecikmeyi ifade ediyor olabilir. ${ }^{[15,19-21]}$ Talusun posterior kısmı, mortis içerisinde yer aldığından, hemen hemen normal yapısını korur. ${ }^{[15,22,23]}$

Kalkaneus kemiği de talus gibi ekinusta ve mediyal rotasyondadır. Böylece, talusun ekinusta durmasına kalkaneusun ekinus ve mediyal rotasyonda durmasının eşlik etmesi, ayak arka kısmında karekteristik ekinovarus pozisyonuna yol açar. Küboid, morfolojik olarak normal olmakla birlikte, mediyale deplase olur ve kalkaneus üzerinde inverte konumdadır. ${ }^{[15,19,24]}$

Navikula, trianguler şekildedir ve küçüktür; mediyale deplase ve inverte olup, hemen her zaman vertikal konumdadır ve şiddetli olgularda neredeyse mediyal malleole dayanır. Navikulanın normal konumuna gelmesi, deltoid ve kalkaneo-naviküler (spring) bağlar, talonaviküler eklem kapsülü, fleksor digitorum longus ve fleksor hallusis longus kaslarının kavşağı (the master knot of Henry) tarafindan önlenir. ${ }^{[15,24,25]}$ Navikulanın mediyale yer değiştirme miktarı ile ayak ön kısmındaki rezidüel adduksiyon arasında ilişki olmadığı bildirilmiştir. ${ }^{[26]}$

Ayağın ön kısmındaki adduksiyon ve supinasyon, talonaviküler ve kalkaneo-küboid eklemlerin subluksasyonuna bağlıdır. ${ }^{[2,19]}$

DÇA'da kalkaneoküboid eklemin ilişkisi de değerlendirilmelidir. Bu eklem, mediyal yönde sublukse olabilir. Subluksasyonun derecesi, deformitenin derecesi ile orantılıdır. ${ }^{[19]}$ Lisfrank eklem ve distalinden gerçekleşen aktif ve pasif hareket, göreceli olarak korunmakla birlikte, hafif sınırlanmıştır. ${ }^{[22]}$

\section{KAS PATOLOJILERi}

DÇA'lı çocuklarda, muhtemelen anterior tibial arterin gelişimsel azalmış perfüzyonuna bağlı olarak, aynı taraf baldır kaslarında hipotrofi ve zayıflık gözlenir. ${ }^{[1,3]}$ Hem uzunluk hem genişlik olarak, bacak boyutunda yarım ya da bir numara hipotrofi görülür (Şekil 1). ${ }^{[27-30]}$ Kas biyopsilerinde, Tip I ve Tip II kas 
liflerinin anormal dağılım gösterdiği bildirilmiştir. ${ }^{[1]}$ Ancak, Tip I ve II liflerin kompozisyonunun, kas örneklerinin tamama yakınında normal olduğunu bildiren araştırmacılar da vardır. ${ }^{[22,31,32]}$

Tibialis posterior ve gastrosoleus kaslarının sıkılığı ve gerginliği, peroneal kasların aşırı gerilme sonucu gevşekliği ve zayıflığı nedeniyle bozulan kas dengesine bağlı olarak, bilek-ayak kinematiği büyük ölçüde değişmiştir. ${ }^{[2,19,24]}$ Plantar fasya ve eşlik eden abduktor hallusis ile fleksor digitorum brevisteki kısalık, ayakta kavus deformitesine yol açar. ${ }^{[19]}$

\section{YUMUŞAK DOKU VE BAĞ PATOLOJiLERi}

Kemiklere ilave olarak; yumuşak doku anomalileri ya da kontraktürleri, deformiteyi arttırıcı etkileri ile beraber, kemik deformitelerini düzeltmeye ve normal dizilimin sağlanmasına direnici rol oynar. ${ }^{1}$ Ligamentöz yapılarda, eşlik eden değişiklikler vardır. Lateral bağlar pek gelişmemiş iken, mediyal yapılar kalınlaşmış ve fibrotik-kontraktedir. ${ }^{[2,19]}$

DÇA'da, ciddi derecede kısalmış olan mediyal ve posterior tarsal bağlar ile tibialis posterior ve gastrosoleus kaslarının sıkılı̆̆ı ve gerginliği nedeniyle, ayak kinematiği büyük ölçüde değişmiştir. Fibrotik ve kontrakte deltoid bağ, kalkaneusu inversiyonda tutar. Naviküler kemik, tibionaviküler, plantar kalkaneo-naviküler bağlardaki fibrozis ve gergin olan tibialis posterior tendonunun çekmesine bağlı olarak, aşırı derecede mediyale deplase ve inverte pozisyonda durur. ${ }^{[19]}$

\section{DAMAR PATOLOJILERi}

DÇA'da damar patolojileri için, özellikle doğumsal dorsalis pedis ve posterior tibial arter yetmezlikleri ile ilgili, farklı görüşler ileri sürülmektedir.[3,28,33-35] Çok nadir olan bu damarsal sorunlar, daha ciddi deformiteli hastalarda bildirilmektedir. ${ }^{[3]}$ Bu tip damarsal anomalilerde, ayakta kısmi nekrozlar bildirilmiştir. ${ }^{[3,36,37]}$ Yirmi yılı geçen kendi pratiğimizde de, iki hastamızda dolaşım sorunu gözlendi. Birinci hastada ameliyat sonrası gelişen ayak iskemisi, düzeltme gerginliği kaldırılınca kendiliğinden düzeldi. İkinci hastada ise, ayak mediyal kısımda, dorsal 1 . webden plantar 1 . webe, başparmak mediyal ucundan topuk mediyaline kadar yayılan yüzeyel tam kat cilt nekrozu gözlemlendi. Tıbbi takibi yapılan bu hastada, zaman içinde tüm nekrotik doku kendini yenileyerek iyileşti.

\section{SINIR PATOLOJILERi}

DÇA, birçok nörolojik sendromun eşlik eden bir özelliği olarak gözlenebilir. Spina bifida gibi norolojik bir rahatsızlık olgusunda, DÇA'nın ikincil patoloji olarak eşlik etmesi bir örnek olarak verilebilir. Eşlik eden diğer sendromlara örnek olarak, serebral palsi ve artrogripozis de sayılabilir. ${ }^{2}$ Yine bir çalışmada, 44 olgunun 18 'inde anormal sinir iletimi ve bu 18 olgunun sekizinde de spinal seviyede anormallikler olduğu bildirilmiştir. ${ }^{[38]}$

\section{AYAK EKLEMLERININ KINEMATIK PATOLOJILERI}

Ayakta eklem hareketleri, eklem yüzeylerinin eğimine ve yapışan bağların yönelim ve yapısına göre belirlenir. Normal ayakta kalkaneus, interosseöz talokalkaneal bağın iç fibrilleri etrafında dönerek, talusun altında hareket eder. Talokalkaneal eklem yüzeylerindeki eğimli kontur nedeniyle, kalkaneus talus altında dönerken adduksiyona, fleksiyona ve inversiyona gelir. Ayak varusa gittiğinde, kalkaneus talus altında adduksiyona ve inversiyona gider. Bu esnada kalkaneus ve talus önünde küboid ve naviküler adduksiyona ve inversiyona gelir. ${ }^{[19]}$

Tarsal eklemler, tek yönlü bir menteşe gibi hareket etmez ama hareket eden eksenlerin etrafinda dönüş hareketi yapar ve simultane hareket ederler. Eğer onlardan bir tanesi bile bloke olursa, diğerleri de fonksiyonel olarak bloke olur. ${ }^{[19]}$

Ayağın posterior kısmının hareketleri ileri derecede kısıtlıdır. DÇA'da, aşırı derecede supinasyondaki ayak arka kısmının hareketlerinde sertlik olmasına karşın, ön kısımdaki göreceli normal durum, bu deformiteyi düzeltmeye çalışan hekim için bir sorun olarak durur.

Normal ayak, kolaylıkla supinasyon ve pronasyona getirilebilir. Ama ÇA pronasyona zorlandığında, sadece ayağın ön kısmı pronasyona gelir, arka kısmı ise gelmez. DÇA'da ana deformite, talo-kalkaneonaviküler eklemdedir. Gerçek bir sferoid eklem olmamasına karşın, sferoid eklem gibi fonksiyon yapar. Bu eklemin diğer sferoid eklemlerden bir başka farkı da, konkav yüzün konveks yüz çevresinde hareket etmesi ve konkav yüzün büyüyüp küçülebilmesidir. Bu eklem plantar fleksiyon ve inversiyona geldiğinde, konkav yüz küçülür; dorsifleksiyona ve eversiyona geldiğinde ise büyür. ÇA deformitesinin dirençli olup olmayışı, plantar fleksiyon ve inversiyonda küçülmüş konkav yüzdeki yumuşak dokuların sertliğinin bir ölçüsüdür. Çünkü bu yüzey, sertlik nedeni ile büyüyemediği için, dorsifleksiyon ve eversiyona gelmekte zorlanır. ${ }^{[19]}$

Talo-kalkaneo-naviküler eklemdeki hareketin merkez noktası, santral talokalkaneal bağların bulunduğu 
yerdir. Bu nokta çevresinde, koronal düzeyde kalkaneus ön ucu naviküler kemik ve diğer ayak kemikleri ile birlikte mediyale doğru dönerken, kalkaneus arka ucu laterale doğru döner ve kalkaneus arka ucu fibulaya yaklaşır. Deformite bu şekli ile sertleştiğinde, kalkaneusun arka ucunu fibulaya birleştiren kalkaneonaviküler bağ kısalır. Ponseti yönteminde kalkaneusun arka ucuna hiç dokunulmadığı için, kalkaneus santral talokalkaneal bağların yapışma yeri çevresinde döner ve kalkaneusun arka ucu fibuladan uzaklaşır. ${ }^{[19]}$

\section{KAYNAKLAR}

1. Kelly DM. Congenital Anomalies ofthe Lower Extremity. In: Canale ST, Beaty JH, editors. Campbell's Operative Orthopaedics, 12th edition, Vol. 2. Philadelphia: Mosby; 2013. p.980-1061.

2. Wynne-Davies R. Family studies and the cause of congenital clubfoot. Talipes equinovarus, talipes calcaneo-valgus, and metatarsus varus. J Bone Joint Surg Br 1964;46:445-63.

3. Herring JA. Disorders of the foot - Congenital Deformities - Congenital Talipes Equinovarus. In: Herring JA, editor. Tachdjian's Pediatric Orthopaedics, 4th ed. Philadelphia, PA: Saunders Elsevier; . 2008. p.785-809.

4. Carroll NC. Preoperative clinical assessment of clubfoot. In: Simons GW, editor. The Clubfoot - The Present and a View of the Future, 1st ed. New York: Springer-Verlag; 1994. p.97-8.

5. Herzenberg JE, Carroll NC, Christofersen MR, Lee EH, White $\mathrm{S}$, Munroe R. Clubfoot analysis with three-dimensional computer modeling. J Pediatr Orthop 1988;8(3):257-62.

6. Howard CB, Benson MK. Clubfoot: its pathological anatomy. J Pediatr Orthop 1993;13(5):654-9.

7. Itohara T, Sugamoto K, Shimizu N, Ohno I, Tanaka H, Nakajima Y, Sato Y, Yoshikawa H. Assessment of talus deformity by three-dimensional MRI in congenital clubfoot. Eur J Radiol 2005;53(1):78-83.

8. Kamegaya M, Shinohara $\mathrm{Y}$, Kokuji $\mathrm{Y}$, Moriya $\mathrm{H}$. Evaluation of pathologic abnormalities of clubfoot by magnetic resonance imaging. Clin Orthop Relat Res 2000;(379):218-23.

9. Kamegaya M, Shinohara $Y$, Kuniyoshi K, Moriya H. MRI study of talonavicular alignment in club foot. J Bone Joint Surg $\mathrm{Br}$ 2001;83(5):726-30.

10. Pirani S, Zeznik L, Hodges D. Magnetic resonance imaging study of the congenital clubfoot treated with the Ponseti method. J Pediatr Orthop 2001;21(6):719-26.

11. Saito $S$, Hatori M, Kokubun $S$, Abe $Y$, Kita A. Evaluation of calcaneal malposition by magnetic resonance imaging in the infantile clubfoot. J Pediatr Orthop B 2004;13(2):99-102.

12. Sullivan RJ, Davidson RS. When does the flat-top talus lesion occur in idiopathic clubfoot: evaluation with magnetic resonance imaging at three months of age. Foot Ankle Int 2001;22(5):422-5.

13. TarrafYN, Carroll NC. Analysis of the components of residual deformity in clubfeet presenting for reoperation. J Pediatr Orthop 1992;12(2):207-16.

14. Duce SL, D'Alessandro M, Du Y, Jagpal B, Gilbert FJ, Crichton L, Barker S, Collinson JM, Miedzybrodzka Z. 3D MRI analysis of the lower legs of treated idiopathic congenital talipes equinovarus (clubfoot). PloS One 2013;8(1):e54100. CrossRef

15. Roye DP, Jr, Roye BD. Idiopathic congenital talipes equinovarus. J Am Acad Orthop Surg 2002;10(4):239-48.
16. Kasser JR. The Foot - Congenital Deformities and Malformations of the Foot (Natural History Through Treatment). In: Morrissy RT, Weinstein SL editors. Lovell \& Winter's Pediatric Orthopaedics, 6th ed. Lippincott Williams \& Wilkins; 2006. p.1258-328.

17. Cuevas de Alba C, Guille JT, Bowen JR, Harcke HT. Computed tomography for femoral and tibial torsion in children with clubfoot. Clin Orthop Relat Res 1998;(353):203-9.

18. Herold HZ. Marcovich C. Tibial torsion in untreated congenital clubfoot. Acta Orthop Scand 1976;47(1):112-7.

19. Köse N. Çarpık Ayak Patoanatomi ve Kinematik. İçinde: $N$ Köse, kurs başk. IX. GKD ve PEV Tanı ve Tedavileri Uygulamalı Kursu Kitapçı̆̆ı. İstanbul: Yeditepe Üniversitesi; 2014.

20. Itohara $\mathrm{T}$, Sugamoto $\mathrm{K}$, Shimizu $\mathrm{N}$, Ohno I, Tanaka $\mathrm{H}$, Nakajima $Y$, Sato $Y$, Yoshikawa $H$. Assessment of the three-dimensional relationship of the ossific nuclei and cartilaginous anlagen in congenital clubfoot by $3-D$ MRI. J Orthop Res 2005;23(5):1160-4.

21. Cahuzac JP, Baunin C, Luu S, Estivalezes E, Sales de Gauzy J, Hobatho MC. Assessment of hindfoot deformity by threedimensional MRI in infant clubfoot. J Bone Joint Surg $\mathrm{Br}$ 1999;81(1):97-101.

22. Wallander HM. Congenital clubfoot. Aspects on epidemiology, residual deformity and patient reported outcome. Acta Orthop Suppl 2010;81(339):1-25. CrossRef

23. Hjelmstedt A and Sahlstedt B. Talar deformity in congenital clubfeet. An anatomical and functional study with special reference to the ankle joint mobility. Acta Orthop Scand 1974;45(4):628-40.

24. Cooke SJ, Balain B, Kerin CC, Kiely NT. Clubfoot. Curr Orthop 2008;22:139-49. CrossRef

25. Ponseti IV. Treatment of congenital club foot. J Bone Joint Surg Am 1992;74(3):448-54.

26. Wallander $\mathrm{H}$, Aurell $\mathrm{Y}$, and Hansson G. No association between residual forefoot adduction and the position of the navicular in clubfeet treated by posterior release. J Pediatr Orthop 2007;27(1):60-6.

27. Ippolito E, De Maio F, Mancini F, Bellini D, Orefice A. Leg muscle atrophy in idiopathic congenital clubfoot: is it primitive or acquired? J Child Orthop 2009;3(3):171-8. CrossRef

28. Merrill LJ, Gurnett CA, Siegel M, Sonavane S, Dobbs MB. Vascular abnormalities correlate with decreased soft tissue volumes in idiopathic clubfoot. Clin Orthop Relat Res 2011;469(5):1442-9. CrossRef

29. Ippolito E, Dragoni M, Antonicoli M, Farsetti P, Simonetti G, Masala S. An MRI volumetric study for leg muscles in congenital clubfoot. J Child Orthop 2012;6(5):433-8. CrossRef

30. Shimode K, Miyagi N, Majima T, Yasuda K, Minami A. Limb length and girth discrepancy of unilateral congenital clubfeet. J Pediatr Orthop B 2005;14(4):280-4.

31. Gray DH, Katz JM. A histochemical study of muscle in club foot. J Bone Joint Surg Br 1981;63-B(3):417-23.

32. Herceg MB, Weiner DS, Agamanolis DP, Hawk D. Histologic and histochemical analysis of muscle specimens in idiopathic talipes equinovarus. J Pediatr Orthop 2006;26(1):91-3.

33. Kruse L, Gurnett CA, Hootnick D, Dobbs MB. Magnetic resonance angiography in clubfoot and vertical talus: a feasibility study. Clin Orthop Relat Res 2009;467(5):1250-5. CrossRef 
34. Dobbs MB, Gordon JE, Schoenecker PL. Absent posterior tibial artery associated with idiopathic clubfoot. A report of two cases. J Bone and Joint Surg Am 2004;86-A(3):599-602.

35. Katz DA, Albanese EL, Levinsohn EM, Hootnick DR, Packard DS Jr, Grant WD, Mann KA, Albanese SA. Pulsed color-flow Doppler analysis of arterial deficiency in idiopathic clubfoot. J Pediatr Orthop 2003;23(1):84-7.

36. David RH, Packard DS Jr, Levinsohn EM, Berkowitz SA, Aronsson DD, Crider RJ Jr. Ischemic necrosis following clubfoot surgery: the purple hallux sign. J Pediatr Orthop B 2004;13(5):315-22.
37. Hootnick DR, Packard DS Jr, Levinsohn EM, Crider RJ Jr. Confirmation of arterial deficiencies in a limb with necrosis following clubfoot surgery. J Pediatr Orthop B 1999;8(3):187-93.

38. Nadeem RD, Brown JK, Lawson G, Macnicol MF. Somatosensory evoked potentials as a means of assessing neurological abnormality in congenital talipes equinovarus. Dev Med Child Neurol 2000;42(8):525-30. 